\title{
Transurethral Prostatectomy Before or After External Beam Radiotherapy: Complications and Reoperation Rates
}

\section{Gabriel Molineros \\ Amichay Meirovitz \\ Marc Wygoda \\ Mohammad Zuaiter \\ Vladimir Yutkin \\ Mordechai Duvdevani \\ Guy Hidas \\ Ofer N Gofrit (D)}

Department of Urology, Hadassah Hebrew University Hospital, Jerusalem, Israel
Correspondence: Ofer N Gofrit Department of Urology, Hadassah Hebrew University Hospital, P.O. Box 12000, Jerusalem, 9| I20, Israel

Tel +972 2-6776874

Fax $+9722-6430929$

Email ogofrit@gmail.com
Purpose: Patients treated by external beam radiotherapy (EBRT) for localized carcinoma of the prostate (CAP) often suffer from urinary obstruction. While most patients can be treated medically, some require transurethral prostatectomy (TURP) for alleviation of obstruction. The consequences of combing EBRT and TURP are controversial. The objective of this study was to evaluate the success and complication rates of TURP combined with EBRT.

Patients and Methods: Between 2001 and 2017, 3501 patients underwent TURP. Sixty-six of them were treated with EBRT for CAP. Surgical complications according to the ClavienDindo (CD) scale and the need for secondary interventions were compared to 66 randomly selected patients operated on for benign prostatic hyperplasia (BPH).

Results: Patients who underwent TURP for BPH were significantly older compared to the patients with CAP with an average of 76.4 (SD 4.3) vs 71 (SD 8.2) years, p<0.0001. Substantial post-operative complications were rare in both groups with only a single case of $\mathrm{CD}$ grade 3 in each group. However, patients with CAP required significantly more secondary surgeries $(21 \%$ vs $6 \%, \mathrm{p}=0.02)$ and significantly more additional interventions (37.9\% vs $13.6 \%, \mathrm{p}=0.0025)$. There was no difference in complication rate, in the need for additional interventions or in the oncological outcome when comparing patients operated before or after EBRT.

Conclusion: The complication rate of TURP done before or after EBRT is low and comparable to surgery for BPH. However, the rates of secondary surgeries and additional interventions in these patients are high (40\%). TURP before or after EBRT provides similar results.

Keywords: carcinoma of the prostate, external beam radiotherapy, transurethral prostatectomy

\section{Introduction}

While effective against cancer, radiotherapy does not improve urinary obstruction. It is estimated that about $7 \%$ of the patients treated with EBRT will require TURP within 5 years after radiotherapy and 13\% "urethral dilatation procedures". According to the clinical scenario, TURP is sometimes done before EBRT (rarely nowadays also leading to the diagnosis of CAP) or after EBRT. The consequences of combing the two procedures are debatable.

Most controversial literature is found in the clinical scenario of TURP after EBRT. Pinkawa et al, in a matched pair analysis, showed that patients undergoing TURP after EBRT have better urinary function score compared to patients who 
underwent EBRT alone. ${ }^{2}$ On the other hand, Liu showed that these patients have a five-fold risk of incontinence compared to non-operated patients (5-year rate of $8 \%$ vs $1.5 \%, \mathrm{p}=0.0015){ }^{3}$ A rate of $27 \%$ new-onset incontinence was reported in another series. ${ }^{4}$ Ishiyama et al in a review of 12 articles concluded that TURP is a risk factor for EBRT induced GU toxicity. ${ }^{5}$

When TURP is done before EBRT, the risk of acute GU grade 2 or more toxicity was $73 \%$ compared to $31 \%$ in patients without a history of TURP $(\mathrm{p}=0.0036)$. These patients also had a lower late freedom from late grade 3 or higher GU toxicity ( $84 \%$ vs $96 \%, p=0.048) .{ }^{6}$ Similarly, in other series, these patients were reported to have a significantly increased risk of GU toxicity (RR 2.78 , 95\% CI 2.56-2.94) and incontinence (5-year rate $10 \%$ vs $6 \%, \mathrm{p}=0.026){ }^{3,7}$ Sandhu et al reported new-onset incontinence rate of $9 \%$ in patients having TURP prior to EBRT. $^{8}$

All the above-mentioned manuscripts focused on EBRT complications (especially on GU toxicity) and compared irradiated patients with or without TURP. In this manuscript, we looked at the data from the surgical perspective, focusing on surgical complications (ClavienDindo) and on the need for further interventions. We compared patients who had TURP prior to EBRT, TURP after EBRT and patients that had TURP for BPH. We also attempt to answer the question should TURP be done before or after EBRT in a candidate for EBRT who suffers from significant urinary obstruction?

\section{Patients and Methods}

The database of 3501 patients who underwent monopolar TURP (ICD-9 code 60.2) between January 2001 and December 2017 was surveyed retrospectively under IRB permission (Committee of the Hadassah Hebrew University Hospital, Jerusalem, Israel, \#HMO-0359-18). Patient consent to review their medical records was not required by the IRB (as long as patient data confidentiality is kept in compliance with the Declaration of Helsinki). Sixty-six patients were treated with EBRT (ICD-9 code 92.29) for localized CAP, either before TURP (34 patients) or after (32 patients). Their clinical $\mathrm{T}$ stages were as follows: $\mathrm{T} 1$ in 4 cases, $\mathrm{T} 2$ in $20, \mathrm{~T} 3$ in 20 and T4 in 4 . In two cases, the stage was not recorded. Radiation was given to pelvic lymph nodes and to the prostate in high-risk patients and to the prostate only in low and intermediate risk, using VMAT technique (Varian-based accelerators). Dose ranged between $76-82 \mathrm{GY}$ to the prostate. Intermediate and high- risk patients received hormonal treatment for 6 months and for 2 to 3 years, respectively. Low-risk patients received $76 \mathrm{~Gy}$ to the prostate without hormonal treatment.

Randomly selected 66 patients operated for benign prostatic hyperplasia (BPH) in the same period and in the same environment served as control group. This control group was selected to represent the "average patient" referred for TURP. Data regarding patient's age, indication for surgery, length of postoperative follow-up, surgical complications according to the Clavien-Dindo (CD) scale and the need for additional transurethral or another intervention in the urinary system were compared.

Continuous variables were compared using the $t$-test and categorical variables using Fisher's exact test. Disease-specific survival rates were analyzed using the Kaplan-Meier method. All statistical tests were twotailed and a $\mathrm{p}$ value smaller than 0.05 was considered significant. The JMP software (Cary, NC) was used for data processing.

\section{Results}

Patients' baseline characteristics are presented in Table 1 . Patients who underwent TURP for BPH were significantly older compared to the patients with CAP with an average of 76.4 (SD 4.3) vs 71 (SD 8.2), $\mathrm{p}<0.0001$. A similar number of patients carried an indwelling catheter before surgery (57\% with CAP and $50 \%$ with $\mathrm{BPH}, \mathrm{p}=0.485$ ). Prostate cancer was found in the pathological analysis of a single patient and high-grade prostatic intraepithelial neoplasia in another patient in the "BPH group". Post-operative follow-up was significantly shorter $(\mathrm{p}=0.01)$ in the CAP group compared to the BPH group (median of 28 months and IQR 14-63

Table I Characteristics of Patients Who Underwent Combined TURP and EBRT and Patients Who Underwent TURP for Benign Disease

\begin{tabular}{|l|c|c|c|}
\hline & $\begin{array}{c}\text { TURP and } \\
\text { Radiotherapy }\end{array}$ & $\begin{array}{c}\text { TURP for } \\
\text { BPH }\end{array}$ & P value \\
\hline Number of patients & 66 & 66 & \\
\hline Mean age at TURP (SD) & $7 \mathrm{I}(8.2)$ & $76.4(4.3)$ & P<0.000I \\
\hline $\begin{array}{c}\text { Indication for surgery: } \\
\text { Symptoms } \\
\text { Indwelling Catheter }\end{array}$ & $\begin{array}{c}28(42.4 \%) \\
(57.6 \%)\end{array}$ & $33(50 \%)$ & 0.485 \\
\hline $\begin{array}{l}\text { Median post-operative } \\
\text { follow-up months (IQR) }\end{array}$ & $28(14-63)$ & $59(22-105)$ & 0.01 \\
\hline 5-year Overall Survival & $75.5 \%$ & $64 \%$ & 0.488 \\
\hline
\end{tabular}


Table 2 Characteristics of Patients Underwent TURP Before or After EBRT

\begin{tabular}{|l|c|c|c|c|}
\hline & TURP Before Radiotherapy & TURP After Radiotherapy & Total & P value \\
\hline Number of patients & 34 & 32 & 66 & $71(8.2)$ \\
Mean age at TURP (SD) & $70.4(8.1)$ & $71.7(8.3)$ & $17.1(18.9)$ & 0.51 \\
PSA ng/mL (SD)* & $15.9(16.7)$ & $18.7(21.6)$ & $8.2(1.1)$ & 0.6 \\
Average Gleason score (SD) & $7.5(1.3)$ & $17(1.2)$ & $18(58 \%)$ & 0.6 \\
Malignant pathology at TURP & $21(62 \%)$ & $85(57)$ & $69(57)$ & 0.055 \\
Average follow-up in months (SD) & $53(52)$ & & \\
\hline
\end{tabular}

Note: *Serum PSA level before treatment.

compared to a median of 59 months and IQR 22-105). Patients operated either before or after EBRT had a similar 5 -year disease-specific survival $(81.9 \%$ and $83.6 \%$, respectively, $\mathrm{p}=0.88$ ). To find whether the timing of TURP (before or after EBRT) influences the results, these groups were analyzed separately. The baseline characteristics of these patients are presented in Table 2 and are comparable.

Significant post-operative complications were rare in both groups (Table 3). CD grade 2 complications (postoperative bleeding, "TUR" syndrome and urosepsis not requiring intensive care hospitalization or reoperation) were more common in the BPH group. The older age of these patients can possibly explain this phenomenon. There was only a single case of CD grade 3 in each group (both patients had bleeding that required reoperation) and no cases of grade 4 or 5 complications. However, patients with CAP required significantly more secondary surgeries $(21 \%$ vs $6 \%, \mathrm{p}=0.02)$ and the significantly more total number of additional interventions (37.9\% vs $13.6 \%, p=0.0025)$. Ten patients with CAP required a second TURP (in 6 TURP was done before and in 4 after EBRT) compared to 3 with BPH (15\% vs $4.5 \%, \mathrm{p}=0.16$ ). Four patients required urethral dilatation (3 had TURP before EBRT- all suffered from bulbar stricture) and one, with penile urethral stricture had

Table 3 Complications and Need for Secondary Interventions in Patients Who Underwent TURP and EBRT and Patients Who Underwent TURP for BPH

\begin{tabular}{|l|c|c|c|}
\hline & $\begin{array}{c}\text { TURP and } \\
\text { EBRT }\end{array}$ & $\begin{array}{c}\text { TURP for } \\
\text { BPH }\end{array}$ & P value \\
\hline Grade 2 complications & I (I.5\%) & $9(7.6 \%)$ & 0.017 \\
Grade 3 complications & I (I.5\%) & I (1.5\%) & I \\
All complications & $2(3 \%)$ & $10(15.1 \%)$ & 0.03 \\
Additional surgery & I4 (2I.2\%) & $4(6 \%)$ & 0.02 \\
Additional non-surgical & II (I6.7\%) & $5(7 \%)$ & 0.18 \\
procedure & & & \\
Any additional intervention & $25(37.9 \%)$ & $9(13.6 \%)$ & 0.002 \\
\hline
\end{tabular}

surgery for $\mathrm{BPH}$ ). When secondary TURP was done after EBRT, typically, the obstructing material was not prostatic tissue but a gray, amorphic, gelatinous material. Histological examination showed that it is composed of fibrin and granulation tissue (Figure 1).

No difference was found in complication rate or in the need for additional interventions when comparing patients operated before or after EBRT (Table 4). The time interval between EBRT and TURP had no significant impact on the rate of secondary interventions $(43.3 \%$ when less than one year and $41.7 \%$ when longer, $p=1)$.

\section{Discussion}

The data presented here shows that almost $40 \%$ of the patients with CAP submitted to TURP, either before or after EBRT, would require additional procedure, surgical (21.2\%) or non-surgical (16.7\%). This is different from what is customary reported in TURP done for BPH $(6 \%$ and $7 \%$ in the current series). No difference was found in the need for additional interventions when comparing patients operated before or after EBRT (Table 4).

Historical series showed that TURP done before EBRT worsens the oncological outcome. ${ }^{9,10}$ In one study prior TURP doubled the risk of metastases compared to nonoperated patients (5-year actuarial risk of $48 \%$ vs $28 \%$, $\mathrm{p}<0.01) .{ }^{11}$ These studies, however, suffer from heavy selection bias (CAP was diagnosed by TURP in many operated patients and by needle biopsy in all nonoperated patients). The oncological outcome in the current series, in which most cases of CAP were diagnosed by needle biopsy was similar for patients operated before or after EBRT, suggesting that the oncological outcome is not a reason to change the order of treatments.

How is it possible to explain the bad outcome of TURP before or after EBRT? This requires an understanding of the normal healing process of the prostatic urethra after TURP and the response of the prostatic urethra to radiation. 


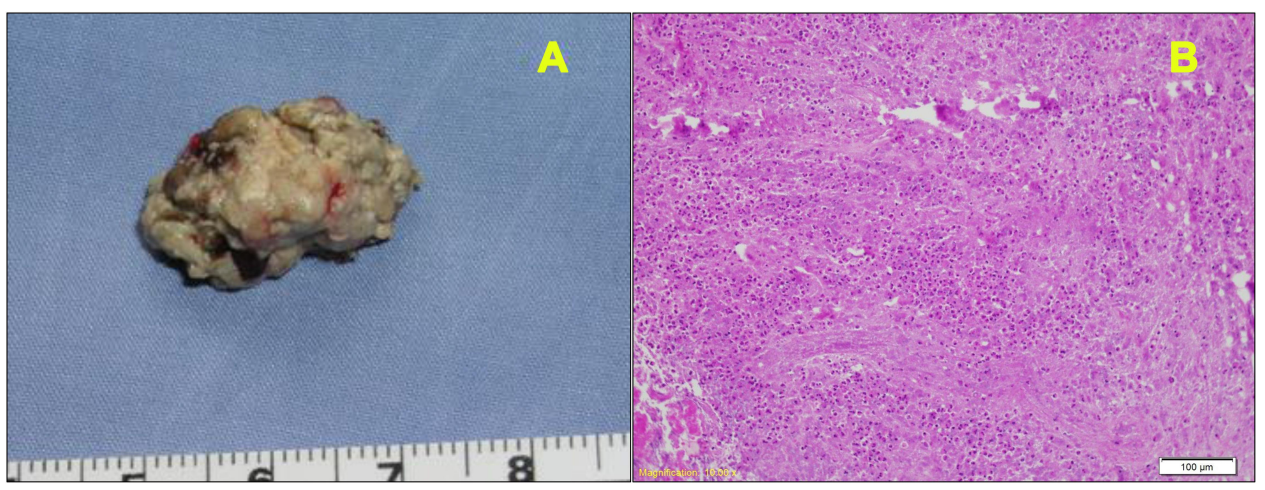

Figure I A 68-year-old man underwent TURP due to severe urinary symptoms unresponsive to alpha-blockers fourteen months after EBRT. Four months later, a second surgery was needed due to re-obstruction. Amorphic material (A) was removed from the prostatic lodge. It was composed of fibrin and granulation tissue (B). Later, this patient required an artificial urinary sphincter to treat urinary incontinence.

The process of urethral healing after TURP was studied in patients who underwent radical prostatectomy at various time periods after TURP. ${ }^{12}$ Coagulation necrosis is the first response. Then, from 6 to 10 weeks gradual reepithelization appears. By 20 weeks, extensive epithelial proliferation and squamous metaplasia originating in the glands and ducts (not from the edges of the urethra) extend into the lumen resulting in complete epithelization. Below the cavity surface, mild chronic inflammatory infiltrate and granulation tissue are gradually replaced by wellorganized underlying inflammatory cell infiltrate. Even by $80-96$ weeks, the squamous cell metaplasia is only partially replaced by urothelium. The process bares an analogy to second-degree burns of the skin or to the healing response of a split-thickness donor skin graft site. In these conditions, dermal appendages are not lost, they

Table 4 Comparison of Complications, Need for Additional Intervention and Survival in Patients Who Underwent TURP Before or After EBRT for Prostate Cancer

\begin{tabular}{|c|c|c|c|}
\hline & $\begin{array}{l}\text { TURP } \\
\text { Before } \\
\text { EBRT }\end{array}$ & $\begin{array}{l}\text { TURP } \\
\text { After } \\
\text { EBRT }\end{array}$ & p value \\
\hline Grade 2 complications & 0 & I (I.5\%) & \\
\hline Grade 3 complications & I (I.5\%) & 0 & \\
\hline All complications & I (I.5\%) & I (I.5\%) & \\
\hline Additional surgery & 9 (26.5\%) & $5(15.6 \%)$ & 0.39 \\
\hline $\begin{array}{l}\text { Additional non-surgical } \\
\text { procedure }\end{array}$ & $4(11.8 \%)$ & 7 (21.8\%) & 0.5 \\
\hline Any additional intervention & $13(38.2 \%)$ & $12(35.3 \%)$ & 1 \\
\hline 5-year overall survival & $64 \%$ & $83.6 \%$ & 0.54 \\
\hline $\begin{array}{l}\text { 5-year disease-specific } \\
\text { survival }\end{array}$ & $81.9 \%$ & $83.6 \%$ & 0.28 \\
\hline
\end{tabular}

provide the source of re-epithelization, and prevent wound contraction that is typical to third-degree burns in which dermal appendages are lost. In a similar fashion, the prostatic urethra does not contract after TURP. In summary, the process of prostatic urethra healing is not complete even by two years after TURP, but if EBRT is indicated after TURP, it should probably be postponed for at least 20 weeks, to give the urethra sufficient time to reach the epithelization phase.

Radiation produces atrophy of the prostate glandular epithelium, shrinkage of the basal cells, stromal fibrosis and vascular changes that include myointimal proliferation with luminal narrowing and accumulation of foamy lipidladen macrophages. ${ }^{13}$ Radiation, therefore, decreases the healing ability of the prostatic urethra by injuring the elements responsible for re-epithelization of the prostatic urethra after TURP (the prostatic glands and ducts) and by decreasing the blood supply to the urethra, further delaying the healing process. TURP after EBRT is, therefore, done on a damaged prostate with decreased healing ability. Thus, it is not surprising that re-epithelization is delayed. There is a constant exposure of the submucosa to urine, continuous irritation of nerve endings, infection, stone formation and accumulation of fibrin and granulation tissue that can obstruct the lumen and can necessitate a second "cleaning" TURP (Figure 1).

EBRT done after TURP meets the prostatic urethra in various stages of re-epithelization. This process starts 6-10 weeks after TURP but continues slowly for years. Thus, interruption of the healing process by radiation can occur even if EBRT is delayed.

The current study is limited by the retrospective methodology of data collection and by the small number of 
patients in the sub-group analyses. The study benefits from the stability of the treatment and follow-up protocols, from the direct comparison to surgery done for BPH in the same environment and from the long follow-up periods.

\section{Conclusions}

TURP done either before or after EBRT is often not a successful procedure and its results are different from that of TURP done for BPH. A second intervention is required by almost $40 \%$ of the patients. Therefore, when considering treatment options in a patient with newly diagnosed CAP who is fit for either surgery or EBRT, the significant urinary obstruction should not be lightly considered and should direct the patient to consider radical prostatectomy and not EBRT.

\section{Funding}

There is no funding to report.

\section{Disclosure}

The authors reported no conflicts of interest for this work.

\section{References}

1. Berge V, Thompson T, Blackman D. Additional surgical intervention after radical prostatectomy, radiation therapy, androgen-deprivation therapy, or watchful waiting. Eur Urol. 2007;52(4):1036-1043. PMID: 17178188. doi:10.1016/j.eururo.2006.12.012

2. Pinkawa M, Klotz J, Djukic V, et al. Transurethral resection of the prostate after radiotherapy for prostate cancer: impact on quality of life. Int J Urol. 2014;21(9):899-903. PMID: 24724611. doi:10.1111/ iju. 12460

3. Liu M, Pickles T, Berthelet E, et al. Urinary incontinence in prostate cancer patients treated with external beam radiotherapy. Radiother Oncol. 2005;74(2):197-201. PMID: 15818868. doi:10.1016/j.radonc. 2004.09.016
4. Polland A, Vertosick EA, Sjoberg DD, et al. Preoperative symptoms predict continence after post-radiation transurethral resection of prostate. Can J Urol. 2017;24(4):8903-8909. PMID: 28832309.

5. Ishiyama H, Hirayama $T$, Jhaveri $P$, et al. Is there an increase in genitourinary toxicity in patients treated with transurethral resection of the prostate and radiotherapy? A systematic review. Am J Clin Oncol. 2014;37(3):297-304. PMID: 22706173. doi:10.1097/COC. 0b013e3182546821

6. Devisetty $\mathrm{K}$, Zorn $\mathrm{KC}$, Katz $\mathrm{MH}$, et al. External beam radiation therapy after transurethral resection of the prostate: a report on acute and late genitourinary toxicity. Int J Radiat Oncol Biol Phys. 2010;77(4):1060-1065. PMID: 20045267. doi:10.1016/j.ijrobp.20 09.06 .078

7. Kim S, Moore DF, Shih W, et al. Severe genitourinary toxicity following radiation therapy for prostate cancer-how long does it last? J Urol. 2013;189(1):116-121. PMID: 23164376; PMCID: PMC3819428. doi:10.1016/j.juro.2012.08.091

8. Sandhu AS, Zelefsky MJ, Lee HJ, et al. Long-term urinary toxicity after 3-dimensional conformal radiotherapy for prostate cancer in patients with prior history of transurethral resection. Int $J$ Radiat Oncol Biol Phys. 2000;48(3):643-647. PMID: 11020559. doi:10.10 16/s0360-3016(00)00714-8

9. Landmann C, Hunig R, Rutishauser G. Adverse effect of transurethral resection on disease-free survival in locally advanced prostatic cancer treated with irradiation. Int J Radiat Oncol Biol Phys. 1993;26 (2):217-221. PMID: 7684037. doi:10.1016/0360-3016(93)90200-f

10. McGowan DG. The effect of transurethral resection on prognosis in carcinoma of the prostate: real or imaginary? Int J Radiat Oncol Biol Phys. 1988;15(5):1057-1064. PMID: 3182338. doi:10.1016/03603016(88)90184-8

11. Forman JD, Order SE, Zinreich ES, Lee DJ, Wharam MD, Mellits ED. The correlation of pretreatment transurethral resection of prostatic cancer with tumor dissemination and disease-free survival. A univariate and multivariate analysis. Cancer. 1986;58 (8):1770-1778. PMID: 3756799. doi:10.1002/1097-0142(19861015) 58:8<1770::aid-cncr2820580832>3.0.co;2-u

12. Orihuela E, Pow-Sang M, Motamedi M, et al. Mechanism of healing of the human prostatic urethra following thermal injury. Urology. 1996;48(4):600-608. PMID: 8886067. doi:10.1016/s0090-4295(96) 00233-6

13. Grignon DJ, Sakr WA. Histologic effects of radiation therapy and total androgen blockade on prostate cancer. Cancer. 1995;75 Supplement:1837-1841.

\section{Publish your work in this journal}

Research and Reports in Urology is an international, peer-reviewed, open access journal publishing original research, reports, editorials, reviews and commentaries on all aspects of adult and pediatric urology in the clinic and laboratory including the following topics: Pathology, pathophysiology of urological disease; Investigation and treatment of urological disease; Pharmacology of drugs used for the treatment of urological disease. The manuscript management system is completely online and includes a very quick and fair peer-review system, which is all easy to use. Visit http://www.dovepress.com/ testimonials.php to read real quotes from published authors. 